\title{
Notes on the vocalizations of Yellow-faced Myna (Mino dumontii) and Long-tailed Myna (Mino kreffti)
}

Peter Boesman

In the following we briefly analyze and compare voice of Yellow-faced Myna (Mino dumontii) and Long-tailed Myna (Mino kreffti). We also try to quantify the extent of any vocal differences using the criteria proposed by Tobias et al. (2010), as a support for taxonomic review. We have made use of sound recordings available on-line from Xeno Canto (XC).

dumontii

Voice includes a variety of low-pitched nasal and growling notes. Some examples illustrated with sonograms:

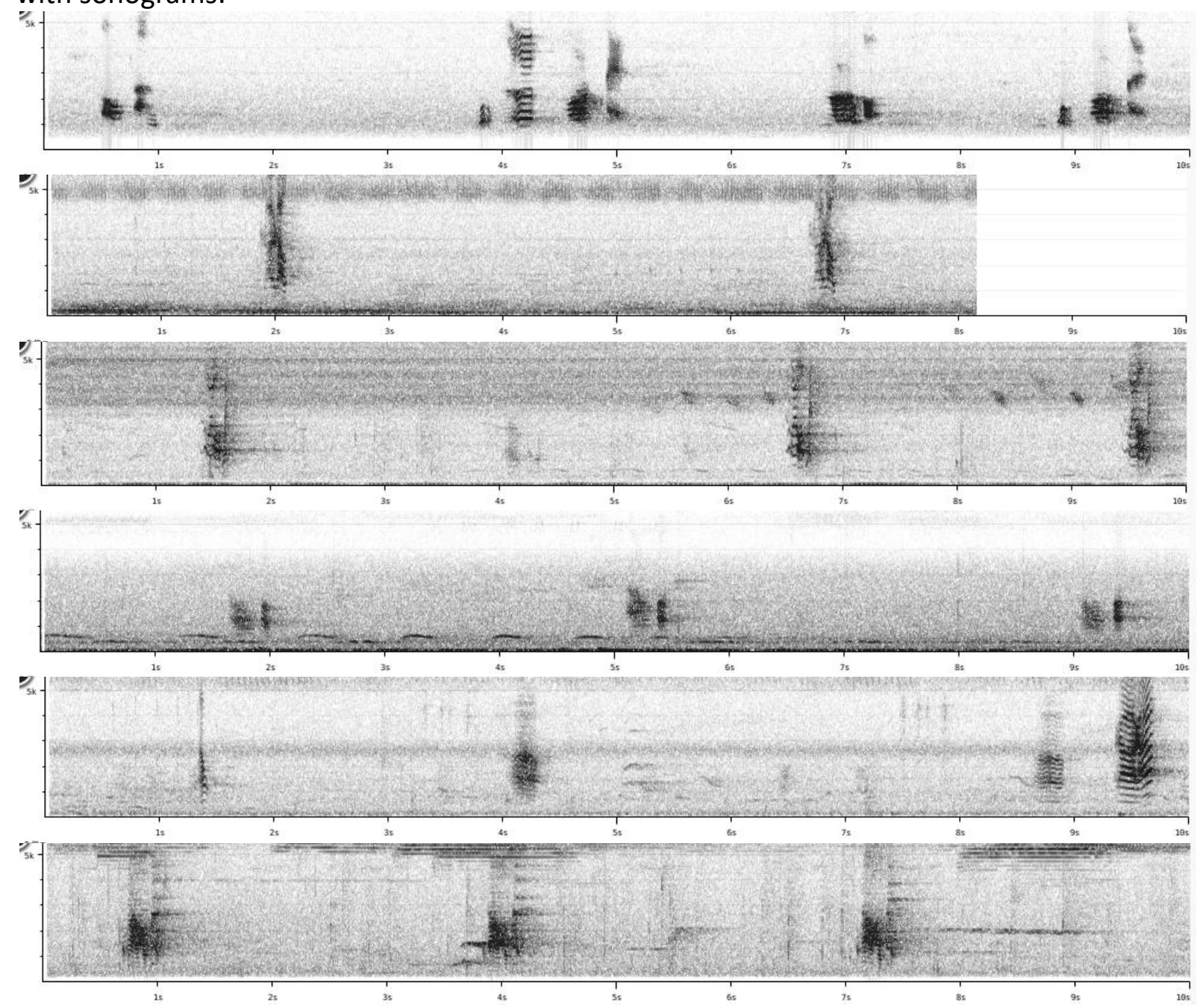




\section{HANDBOOK OF THE

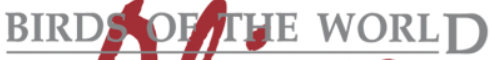 \\ Aluve}

\section{ORNITHOLOGICAL NOTES}

\section{kreffti}

Voice includes a variety of squealing or squawking, rather high-pitched notes, which are quite drawn-out. Some examples (including from the Bismarck archipelago):
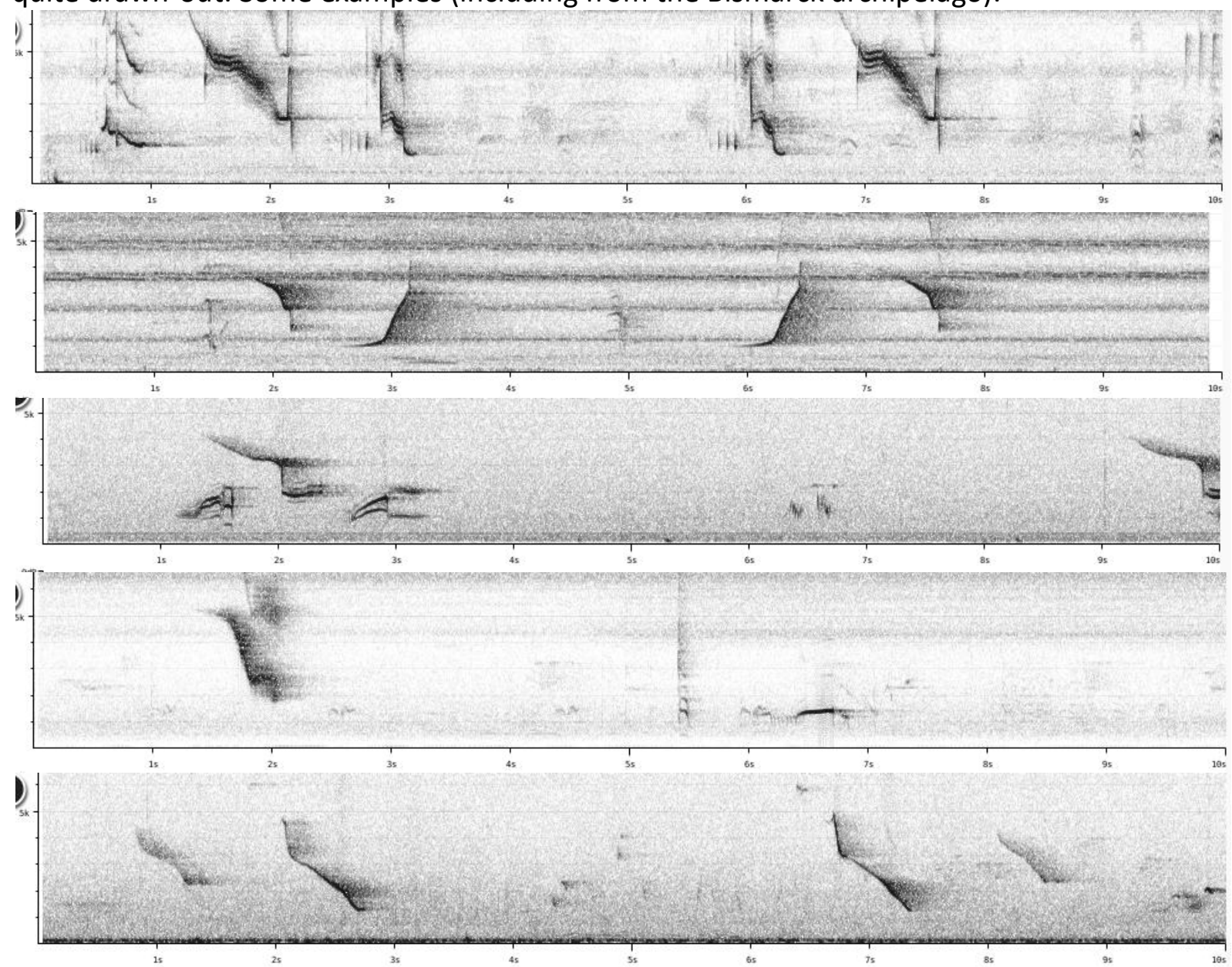

There can be little doubt about the vocal distinctiveness of both taxa.

Based on the note frequency range (of the fundamental frequency) and the average length of notes, a total vocal score of about $3+2=5$ seems likely.

This note was finalized on 18th April 2016, using sound recordings available on-line at that moment. We would like to thank in particular the sound recordists who placed their recordings for this species on XC: Patrik Åberg, Mike Catsis, Phil Gregory, Niels Krabbe, Frank Lambert and Bas van Balen.

\section{References}

Tobias, J.A., Seddon, N., Spottiswoode, C.N., Pilgrim, J.D., Fishpool, L.D.C. \& Collar, N.J. (2010). Quantitative criteria for species delimitation. Ibis 152(4): 724-746. 


\section{Recommended citation}

Boesman, P. (2016). Notes on the vocalizations of Yellow-faced Myna (Mino dumontii) and Long-tailed Myna (Mino kreffti). HBW Alive Ornithological Note 297. In: Handbook of the Birds of the World Alive. Lynx Edicions, Barcelona. (retrieved from http://www.hbw.com/node/1251746 on 13 October 2016). 